\title{
De Elton Mayo a Ivar Oddone: redescobrir a instrução ao sósia
}

Yves Clot $^{1}$

O presente texto foi publicado originalmente como prefácio de uma obra de Yves Clot em homenagem a Ivar Oddone. Decidimos publicá-lo no formato de artigo, com a autorização do autor, por considerarmos que traz importantes e atuais contribuições para o campo do trabalho em intercruzamento com diversas teorias: Clínica da Atividade, Ergologia, Ergonomia, Saúde do Trabalhador, dentre outras. Neste texto, Yves Clot retoma aspectos significativos da obra de Ivar Oddone e tece reflexões sobre aspectos originais dessa, nem sempre considerados pelos estudiosos da área. Assim, faz uma análise comparativa com as propostas apresentadas por Elton Mayo, as quais se sagraram como importante ferramenta para o desenvolvimento do capitalismo industrial sob a suposta égide do enaltecimento do aspecto humano nas situações de trabalho. Ao contrário das concepções e práticas de Mayo, que foram efetivamente voltadas para o aumento da produtividade das empresas e, portanto, para a exploração dos trabalhadores, Oddone buscou reconhecer e valorizar o saber dos operários, com o intuito de que esse se configurasse como um contrapoder ao ampliar o seu poder de agir na situação de trabalho, aspectos que são amplamente discutidos por Clot no texto que ora apresentamos. ${ }^{2}$

Palavras-chave: Ivar Oddone, Instrução ao sósia, Psicologia do trabalho.

From Elton Mayo to Ivar Oddone: rediscovering the instruction to the double

This text was initially published as a preface written by Yves Clot in honor of Ivar Oddone. We decided to publish it as an article, authorized by the author, as we believe that it brings important and current contributions to the field of work, in interseccion with several theories: Clinic of Activity, Ergology, Ergonomics, Worker's Health, among others. In this text, Yves Clot takes up highlights of Ivar Oddone's work and produces reflections about its original aspects, not always considered by experts in the field. Thus, he makes a comparative analysis with those aspects and the proposals presented by Elton Mayo, which have become an important tool for the development of industrial capitalism under the supposed appreciation of the human sides in work situations. Contrary to Mayo's conceptions and practices, which were aimed at increasing the productivity of companies and, therefore, at the exploitation of workers, Oddone sought to recognize and value the knowledge of workers, intending that this was used as a kind of counterpower, by expanding its power to act in the work situation, points that are widely discussed by Clot in the text that we present now.

Keywords: Ivar Oddone, Instruction to the double, Work psychology.

1 Professor emérito do CNAM (Conservatoire National des Arts et Métiers), titular da cátedra de psicologia do trabalho e criador da Clínica da Atividade. https://orcid.org/0000-0001-5934-8050

2 Tradução de Matilde Agero Batista, docente do Departamento de Psicologia da Universidade Federal de São João del Rei (UFJS), e de Maristela de Souza Pereira, docente do Instituto de Psicologia da Universidade Federal de Uberlândia (UFU). Contatos: matilde@ufsj.edu.br e maristela.pereira@ufu.br. Título original: D’E. Mayo à I. Oddone. redecouvrir l'instruction au sosie. Agradecemos a Fábio de Oliveira pela gentil revisão técnica do texto. 


\section{Introdução}

Dode-se questionar o porquê de se retomar a obra de Ivar Oddone tantos anos depois. Quando o livro Esperienza operaia, coscienza di classe e psicologia del lavoro ${ }^{3}$ foi publicado pela primeira vez na França, seu objetivo era dar a conhecer uma experiência original, a experiência de um encontro singular entre a iniciativa transformadora de trabalhadores da indústria automobilística na Itália e o profissionalismo renovado de uma equipe de investigadores de Turim especializada em medicina e psicologia do trabalho. Aquela experiência social questionou as maneiras de colocar os problemas de saúde no trabalho nessas disciplinas. Mas também levantou a questão da concepção de sindicalismo, sua relação com a empresa no setor industrial e o sistema de relações profissionais. Tal experiência era tão incrível que foi rapidamente notada pelos melhores representantes da sociologia do trabalho na França, que viram nela algo inigualável.

\section{O efeito Hawthorne persiste por muito tempo}

Mas por que essa obra, ligada a eventos agora tão distantes, ainda pode ser útil tantos anos depois? Pessoalmente, acredito que a experiência de Ivar Oddone e seus colegas ao longo dos anos 1960-1970 é tão importante - por razões opostas - quanto a da equipe de Elton Mayo na fábrica de Hawthorne da Western Electric no início dos anos 1920. E, talvez, tenha até mesmo uma importância ainda maior, pelo menos de um certo ângulo. Na verdade, a obra de Oddone nos lega, além do acesso à experiência social única que nos transmite, a história de uma das técnicas de análise de trabalho - a instrução ao sósia - que foi um marco na psicologia do trabalho ${ }^{4}$. Esta nova apresentação, aqui realizada, tem, portanto, dois objetivos. O primeiro é enfatizar a modernidade dessa experiência social para mostrar que a forma como o problema do trabalho é abordada por Oddone e seus colegas ainda está um passo à frente do que nós procuramos fazer na atualidade ${ }^{5}$. O segundo objetivo é procurar esclarecer a originalidade dessas "instruções ao sósia", que eu vejo cada vez mais como uma contribuição importante para a psicologia contemporânea.

Vamos começar com um pouco de história para entender no que a experiência da Fiat é, em certo sentido, o oposto do que foi a da Western Electric, o oposto do que poderíamos chamar de uma gestão da subjetividade através da escuta (Clot \& Gollac, 2014). Basta voltar à experiência de Mayo, em Hawthorne, entre 1924 e 1932, para encontrar, indubitavelmente, a primeira experiência significativa desse tipo de gestão. Nessa experiência, que está na origem da chamada escola de "relações humanas", os pesquisadores notaram rapidamente um aumento da produtividade ao observarem os operários trabalharem, sem que fosse necessária qualquer alteração nas condições de trabalho, para além da sua própria presença. Essa presença artificial manifestava um tipo de consideração dada aos trabalhadores pelos pesquisadores e, desse modo, pela própria administração da empresa. A eficácia produtiva desse reconhecimento foi tal que acabamos chamando-o "efeito Hawthorne" na literatura psicossociológica. Na verdade era, sobretudo, um sintoma da limitação social da empresa que se manifestou na ocasião, revelando a massa de inibições habituais no trabalho, inibições rompidas pela investigação então em curso. Essa limitação geralmente se manifestava por vários sintomas de resistência dos trabalhadores. No contexto experimental da investigação de Mayo, a "depreciação" habitual dos trabalhadores pela organização se revelava por outros meios, do que se deduz que as conclusões da pesquisa de

3 Autoria de Ivar Oddone, Alessandra Re e Gianni Briante, publicado originalmente na Itália em 1977. A primeira versão traduzida para o português está em vias de ser publicada, sob a coordenação de Daisy Cunha, Francisco de Paula Antunes Lima e Maria Elizabeth Antunes Lima. (Nota das tradutoras)

4 A técnica original da instrução ao sósia, desenvolvida por Oddone e colaboradores, é descrita em detalhes em Oddone e Re (2017). (Nota das tradutoras)

5 A publicação original data de 2015. (Nota das tradutoras)

6 Todas as passagens entre aspas são grifos do original. (Nota das tradutoras) 
Hawthorne "consagram a primazia de fatores sociais sobre o fator humano", como observa Friedmann (1946, p. 323), em uma análise agora considerada clássica.

No entanto, ao invés de enxergarem aí um novo problema para lidar - um problema social - a escola das relações humanas e a direção das empresas pensaram que poderiam, ao contrário, encontrar uma solução nestes termos: a integração artificial dos trabalhadores, atuando sobre as relações entre as pessoas para desenvolver um reconhecimento "factício". O principal achado de Mayo foi que a produtividade aparentemente aumentava quando as relações de trabalho levavam em conta as emoções pessoais nas situações de trabalho. Assim, os organizadores optaram pela primazia do "fator humano" sobre o "fator social", o oposto das descobertas mais profundas baseadas nessa investigação, como aquelas empreendidas por Friedmann. Eles atribuíram ao problema social uma solução "psicológica". Desse ponto de vista, Eva Illouz estava certa ao notar que "o caráter terapêutico da intervenção de Mayo na empresa não foi suficientemente acentuado" (Illouz, 2006, p. 32). Ao analisar as técnicas de entrevista que se seguiram às observações do trabalho na fábrica, ela concluiu que Mayo, psicanalista junguiano de formação, de fato mobilizava uma modalidade de entrevista terapêutica que "introduziu o imaginário psicanalítico no interior do meio de trabalho" (p. 32), aspecto que, aliás, Friedmann já tinha observado em 1946.

A concepção por detrás das entrevistas realizadas na Western Electric é o protótipo das "terapêuticas" do reconhecimento intersubjetivo desconectadas do trabalho real. Ela apela para o sentimento experimentado pelos trabalhadores "de serem importantes e de terem sido escolhidos" (Illouz, 2006, p. 36). A entrevista terapêutica, mobilizando a história familiar, sem que a intenção de Mayo tenha sido claramente premeditada, leva, segundo ele, aos "bloqueios afetivos à comunicação tanto dentro como fora da fábrica" (Mayo, 1945, p. 81). Portanto, esta é, já naquela época, a construção de um espaço dedicado à escuta, no qual a experiência do conflito entre trabalhadores e dirigentes se dissolve na linguagem das emoções (Illouz, 2006, p. 40). Trata-se, de acordo com o protocolo da entrevista, desenvolvido não sem condescendência, de escutar, de preferência sem falar, o que o trabalhador "quer dizer", o que "ele não quer dizer" e "o que ele não pode dizer sem ajuda", sem nunca esquecer que esta é uma "confidência pessoal que não deve ser divulgada a ninguém" (Mayo, 1945, pp. 73-74).

Por tê-lo feito em outro lugar (Clot \& Gollac, 2014), não insistirei aqui sobre os usos que têm sido feitos a partir desta opção "psicológica" na análise e gestão do trabalho depois de quase uma centena de anos. Suas consequências estão na base da ingenuidade social recorrente - longe de serem tão graves como na investigação Hawthorne - em que se apoiam regularmente as "belas histórias" de uma "empresa isenta" (Getz, 2012). Agora sabemos como essa "psicologia positiva" finalmente orientada para o padrão de "bem-estar" ou para aqueles de liderança pessoal, natural ou restaurado (Getz, 2012, p. 12; Cottraux, 2012) pode ser usada para preencher as brechas do "fator social"; e até mesmo converter em controle social o que começou pela expressão subjetiva das emoções. Conhecemos os segredos sociais de uma compaixão superficial. Eles podem levar a um beco sem saída: o "direito à saúde" - por exemplo, o de ser reconhecido em seu trabalho como uma vítima que se deve indenizar - pode muito bem ser combinado com uma glorificação do desempenho individual, diferentemente de uma "responsabilidade pela saúde" permanente (Bellashsen, 2014). Assim, podemos, por exemplo, hoje na França, considerar reconhecer o burnout como doença profissional e simultaneamente definir a saúde mental como uma resistência à toda prova: "Uma pessoa com boa saúde mental é alguém que se sente suficientemente confiante para adaptar-se a uma situação que não pode mudar em nada" (Centre d'analyse stratégique, 2010, p. 24). Uma vez que a saúde mental é confundida com a capacidade de suportar o insuportável, seria necessário, em seguida, reconhecer como "doentes" aqueles que não atingiram esse nível de resistência.

Certamente, há um longo caminho desde esse higienismo invasivo até a experiência fundadora de Mayo. Mas, olhando o trabalho como uma relação de pessoa a pessoa, como o terreno, entre outros, de uma realização de si abstrata, a psicologia industrial adaptativa que se seguiu abriu o caminho para a prescrição das "competências emocionais"; tanto para "corrigir as deficiências, como para programar a eficiência”, como foi visto R. Castel (2011, p. 61). O 
trabalho de Oddone segue uma direção inversa. Ele define a adaptação profissional, individual e coletiva, como a capacidade concreta de mudar o trabalho através de sua própria iniciativa. A saúde dos trabalhadores, de forma geral, ganha muito com essa independência conquistada na transformação efetiva; muito mais do que se colocando sob o controle de uma expertise médicopsicológica, como evidenciam repetidas experiências (Fernandez, 2009) ou ainda o exemplo japonês recentemente analisado por J. Kitanaka (2014).

Comentando o livro de 1946 de Friedmann, Problemas humanos do maquinismo industrial, G. Canguilhem (2015) colocou bem o problema não resolvido pela pesquisa da Western Electric. Essa não resolução "revela a incapacidade dos investigadores, agentes a serviço da empresa, de ver em sua posição a empresa com os olhos dos trabalhadores, ver a empresa na sociedade em vez de fazer coincidir a sociedade e a empresa" (2015, p. 305). Ele observa, com Friedmann, que a investigação de Mayo julga "irracionais" os motivos da resistência operária à racionalização, o que significa considerá-los por fim como anormais. Esse autor conclui, sem saber que essa conclusão será um dia considerada o ponto de partida do trabalho de I. Oddone:

O que escapou aos psicólogos da investigação de Hawthorne é que os trabalhadores apenas tomariam por autenticamente normais as condições de trabalho que eles mesmos tivessem instituído em referência aos valores próprios e não emprestados, que a situação de trabalho que eles tomariam como normal seria aquela produzida por eles mesmos, de si mesmos para eles mesmos. Todo homem quer ser sujeito de suas normas. A ilusão capitalista é acreditar que as normas capitalistas são definitivas e universais, sem pensar que a normatividade não pode ser um privilégio (Canguilhem, 2015, p. 306).

É precisamente daqui que parte Ivar Oddone. Ou melhor, essa é a principal diferença: é da experiência concreta vivida e revivida das consequências dessa ilusão que partem os trabalhadores da Fiat, em 1969, em cooperação com Oddone realizada através de um projeto na Universidade de Turim. Para eles, na conjuntura histórica que descreveremos resumidamente, o que Canguilhem chama normatividade, ou seja, o poder de criar e recriar as normas, definitivamente não é mais um privilégio. Nenhum grupo social deteria mais o monopólio legítimo naquele momento. E, acertando as contas com o trabalho de Elton Mayo, ao examinar a diferença entre ele e Taylor, Oddone escreveu:

Pensando bem, a ambição de Mayo é muito semelhante à de Taylor na medida em que, tanto um como o outro, buscam substituir os aspectos irracionais $^{7}$ da organização do trabalho pela racionalidade científica. É verdade que Mayo acredita que a direção deve considerar os problemas dos trabalhadores, mas ele ainda pensa que é o especialista que deve conceber as prescrições para resolvê-los (Oddone, 1981, p. 173).

Daí vieram as transformações que ganharam grande amplitude na atualidade, aquelas que poderiam ser designadas como uma "superumanização gerencial" para falar de uma gestão psicológica da empresa (Linhart, 2015). Daí seguiram também tentativas, já descritas por Oddone (1981, p. 174), de se afastar da rigidez taylorista reforçando o papel e a autonomia do grupo de trabalho. E, até hoje, continua-se a acreditar que a forma de os empregados se expressarem pode ser concedida, ou mesmo prescrita. Ao discutir esse movimento psicológico depois de Mayo, com uma menção especial para A. Maslow, que alguns acreditam poderem invocar ainda hoje (Getz, 2012), Oddone observou em 1977: "Ninguém pode negar o valor dessa profusão de pesquisas, mas se deve notar que elas são mutiladas pelo fato de que atribuem somente ao especialista a tarefa de resolver o problema da desmotivação no trabalho" (Oddone et al., 1977, p. 175). Em certo sentido, tudo está dito. É esse diagnóstico que, aos meus olhos, faz ainda hoje da obra de Oddone a marca de uma experiência social que rivaliza em importância com a de Mayo.

7 Os trechos destacados em itálico também são grifos do original. (Nota das tradutoras) 


\section{O retorno das "relações humanas" ao trabalho}

Compreendo que o termo rivaliza tem um sentido forte. Eu quero dizer com isso que estão aqui as vias ainda e sempre concorrentes no campo da análise do trabalho considerado como transformação. Lá, onde Mayo identifica primeiro um problema de relações humanas a corrigir graças ao especialista, Oddone encontra graças a seus interlocutores - sem o saber - a análise clássica de P. Naville. Devemos partir da qualidade do trabalho: "o trabalho qualificado é aquele que é bem feito" (Naville, 1955/2012, p. 18). E isso é assim, diz Naville citando T. Veblen, porque o homem "gosta do trabalho eficaz e odeia esforços inúteis. Ele compreende as vantagens da funcionalidade e da competência, bem como os inconvenientes do absurdo, do desperdício ou da incompetência" (Naville, 1955/2012, p. 18). Em outras palavras, aqueles que trabalham têm os seus próprios meios para superar a desmotivação no trabalho, desde que a organização do trabalho seja um verdadeiro recurso para eles. Desde que essa não desperdice os seus esforços, não dissipe sua energia; em resumo, desde que ela impeça o absurdo do trabalho desperdiçado pela falta de liberdade de ação. Com Oddone, as "instruções" podem vir de outros lugares além do especialista, no momento em que encontramos um "sósia" a quem transmitir nossa experiência. As "relações humanas" podem assim ser regeneradas.

Quando Oddone fez suas análises, a situação social era muito distante daquela que conhecia Mayo, configurando-se como um momento histórico que justamente redefine a liberdade de ação. Era o contexto de um movimento social que as gerações de hoje, sem dúvida, têm dificuldade de imaginar e que deu esse tom militante e "provocador" à escrita de Oddone, como observou J. Leplat (1982, p. 373). Agora, estamos longe também dessa época. No entanto, o interesse de rever a conjuntura de então é apenas histórico no mau sentido da palavra, isto é, voltado ao passado. O que é interessante, ao contrário, é que esse passado não é realmente passado. Ele está longe, é muitas vezes recalcado, mas os problemas daquela época, alojados no trabalho humano, ainda existem e podem ser até mais agravados por esse recalque. Enquanto se aguarda uma solução, eles se apresentam de novo hoje como uma urgência no mundo do trabalho, devendo ser considerados se quisermos evitar que eles envenenem a sociedade.

Um livro recente nos ajudará a entender o quanto o legado de Oddone pode ser útil, se usado para além de seu contexto original. Na Cidade do trabalho, escrito em 1997, Bruno Trentin (2012) dá ao contexto da época todo o seu significado contemporâneo. Aquele que naquela época exerceu importantes responsabilidades sindicais na metalurgia italiana e que se tornou então o principal dirigente da CGIL mostra, com agudo sentido da gravidade dos problemas atuais, o uso que ainda pode ser feito do espírito geral dessa herança, embora surpreendentemente - nunca se refira diretamente à obra de Oddone. Obviamente que as reflexões de Trentin, como apontado por A. Supiot (2012), estão muito envolvidas no debate político de sua época. Mas, graças à originalidade de seu trabalho, um casamento único da alta cultura europeia com um sentido do concreto nunca negado, temos um precioso instrumento de análise. A sua longa experiência prática e a sua grande liberdade no que se refere ao sindicalismo deram-lhe autoridade para fazer uma crítica - diga-se radical - às políticas de esquerda, mesmo ele que aliás nunca admitiu, nem nos fatos nem na teoria, a arrogância liberal. O ponto de vista de Trentin é certamente um ponto de vista sindical e, embora muito original, não pode ser superposto ao ponto de vista do psicólogo do trabalho. Mas temos que concordar que suas análises, realizadas o mais próximo possível do real, que também é o nosso nas intervenções dentro das organizações, lançam uma luz particular sobre o que pesa na profissão de pesquisador e de intervenientes que exercemos. Elas também lançam luz sobre nossas margens de manobras efetivas na ação, lembrando aquelas que os médicos e psicólogos do trabalho italianos haviam então conquistado.

Assim, para ele, existe uma tensão ainda maior hoje do que na época, reforçada pelo aumento dos serviços, entre a necessidade de ultrapassar as modalidades de produção padronizadas do fordismo, por um lado, e o trabalho subordinado que está sempre em expansão, pelo outro. As iniciativas dos assalariados, seja para controlar a qualidade dos produtos e serviços, 
seja para corrigir as variações da produção de acordo com o "cliente", são cada vez mais imperativas. Podemos evitar o absurdo mencionado por Naville, pois no momento em que o trabalho é cada vez menos previsível pelas hierarquias é preciso solicitar mais o poder de iniciativa dos trabalhadores. Isso certamente oferece novos graus de liberdade para a reapropriação do trabalho de organização pelos operadores ou pelos próprios agentes, para que possam afirmar "o seu gosto pelo trabalho eficiente", pondo em jogo os seus próprios critérios de qualidade do trabalho. Mas o mínimo que se pode dizer é que esse movimento é frustrado, que essa iniciativa é "engolida".

O desenvolvimento deste poder de agir sobre o próprio trabalho, mesmo em nome da sua qualidade, não é aceito em sua essência na maioria das empresas, privadas ou públicas. Diante desse problema, a lucidez é essencial. Nada acontecerá espontaneamente:

Pelo contrário, na ausência de uma iniciativa sindical coerente capaz de gerar um consenso duradouro sobre objetivos confiáveis entre os trabalhadores envolvidos, e sem uma intervenção pública capaz de promover - inclusive com os recursos da coletividade - a experimentação de formas diferenciadas e negociadas de organização do trabalho, é provável que a maioria das empresas, confrontada com a contradição que acabamos de referir, tente enfrentá-la acentuando, e não atenuando, as características autoritárias da fábrica taylorista (Trentin, 2012, p. 60).

Trentin, portanto, não é ingênuo no que diz respeito à estrutura hierárquica. Ele crê que essa é capaz de "assumir a liderança" e infelizmente "radicalizar seu poder de coerção sobre o trabalhador" (p. 61).

\section{Um sindicalismo de volta ao trabalho?}

Mas sua crítica, já em 1997, toca diretamente o contexto do qual nos ocupamos com a obra de Oddone. Na verdade, ela se volta também contra a esclerose de um sindicalismo que não pôde e não soube manter seus compromissos iniciais por muito tempo no que diz respeito a experiências concretas, em verdade heterodoxas, sobre a qualidade do trabalho, que ocorreram entre meados dos anos 1960 e início dos 1970. Porém, no final dos anos 1960 e especialmente durante o "outono quente" de 1969, a Itália experimentou uma mobilização sem precedentes de milhões de trabalhadores a favor da conquista dos direitos formalmente reconhecidos na negociação coletiva das condições de trabalho no próprio lócus onde o trabalho subordinado ocorre: controle e prevenção da saúde e segurança no trabalho, formação e investigação massiva para determinar os efeitos do taylorismo na saúde física e mental e no cotidiano do trabalhador, o abandono de tecnologias perigosas, a negociação de investimentos para eliminar as causas da nocividade, da penosidade e do mal-estar. Circulando entre delegados eleitos, cujo trabalho decisório formou um novo centro de gravidade do poder organizacional, desenvolveu-se um gênero de ação em que a negociação e a defesa dos direitos humanos não eram mais "relegadas à simples corrida salarial" (Trentin, 2012, p. 75). Essa ruptura com a velha lógica compensatória e reformista da esquerda e do sindicalismo permitiu precisamente um encontro inédito entre o mundo do trabalho e o mundo científico. Tal ruptura "imprimiu um novo curso à pesquisa em medicina ocupacional" (Trentin, 2012, p. 76). É nesse contexto que devemos situar o estabelecimento de uma bolsa de trabalho entre os trabalhadores da Fiat em Turim e a equipe de I. Oddone, em que a universidade ${ }^{8}$ utilizou as 150 horas concedidas aos delegados de linha para formalizar a sua experiência através das instruções ao sósia desenvolvidas nesse processo. ${ }^{9}$ Essa conjuntura, certamente efêmera, foi também, segundo Trentin, a do encontro forçado e da contaminação recíproca de duas culturas relativas à ação e decisão coletiva: a cultura operária,

8 Università degli Studi di Torino, onde Oddone foi posteriormente professor de Psicologia do Trabalho. (Nota das tradutoras)

9 Após reivindicação dos trabalhadores organizados, foi incorporado à legislação italiana o direito de algumas categorias usarem 150 horas anuais remuneradas de trabalho para fins de estudo. Mais informações podem ser obtidas em Pereira (2017a). (Nota das tradutoras) 
de uma tradição socialista e marxista, e o "núcleo duro" de uma cultura de tradição cristã, tomando emprestado tanto do personalismo de E. Mounier quanto dos escritos de S. Weil "uma potencialidade subversiva da ordem estabelecida" (Trentin, 2012, p. 77). A defesa intransigente da integridade física e moral da pessoa foi então "uma provocação forte e fecunda que abalou profundamente" o sindicalismo italiano (p. 78). O próprio Trentin se mostra ainda tão marcado por essa contaminação que toma emprestado, sem mencionar (até onde eu sei), o título de sua obra A cidade do trabalho desta tradição cristã também nutrida por P. Ricoeur e retomada no campo da economia por um heterodoxo tão engajado como Henri Bartoli:

Uma cultura, para ser honesto, deve ser combativa, isto é, tomar o partido do ser humano e dirigir sua posição contra qualquer regime que trate o homem como meio, em vez de tratá-lo como um fim. Ela deve exercer esta função em qualquer situação: a Palavra não pode ser rebaixada à categoria de um simples comentário sobre o Trabalho ou de uma submissão cega à ideologia dos movimentos ou do Estado que constrói a Cidade do Trabalho (sou eu quem sublinha), uma vez vencida a civilização do dinheiro, sem colocar em risco a civilização $\left(1957\right.$, p. 301). ${ }^{10}$

Desnecessário dizer em que medida podemos encontrar aqui algo para compreender o próprio alcance da principal inovação psicológica de Oddone e seus colegas, a instrução ao sósia, na qual nos concentraremos a seguir: a ideia de que a palavra não pode ser um simples comentário do trabalho, pois é muito mais do que isso, que encontra um apoio sólido na psicologia vigotskiana das relações entre atividade real, pensamento e linguagem (Vigotski, 1997).

Restam hoje duas lições que podem ser tiradas da obra de Trentin para melhor compreender o contexto em que se deu a experiência da Fiat em Turim e, especialmente, os novos contextos que aquela experiência pode ainda ajudar a produzir. A primeira lição assinala os limites dessa iniciativa histórica do sindicalismo italiano e permite compreendê-los. A segunda ajuda a sustentar uma ideia forte: essa experiência está, ainda hoje, um passo à frente. Não só do ponto de vista do desenvolvimento do poder de agir sobre o próprio trabalho, mas também do ponto de vista de uma clínica do trabalho em psicologia.

Primeiro, vamos falar sobre o curto espaço de tempo desse experimento social realizado em grande escala, mas sem um condutor. ${ }^{11}$ Ele ocorreu, no máximo, em uma década, ou seja, durante um período de tempo similar ao experimento de Mayo na Western Electric Company. A primeira edição do livro Esperienza operaia na itália é de 1977 e coincide com o fim deste novo rumo sindical e político. O diagnóstico de Trentin é claro:

Este breve período foi rapidamente ultrapassado e esquecido. A partir do final da década de 1970, de fato, quase não existiam vestígios dos conteúdos reivindicativos específicos e dos resultados culturais e políticos daquele período de lutas sociais na memória dos partidos de esquerda italiana (Trentin, 2012, p. 83). ${ }^{12}$

Qual é o argumento de Trentin? A cultura social de esquerda não teria "digerido" esta entrada em campo das forças que vinham de dentro da fábrica e assumiam a qualidade do trabalho como fonte de saúde, de liberdade e de eficiência. Essas forças se libertavam dos esquemas de reparação e indenização por danos gerados no trabalho, vistos até então como intocáveis, politicamente "neutros" em seu arranjo. Foi a reação da esquerda e mesmo de um certo sindicalismo, mas antes de tudo da esquerda, segundo Trentin - antes mesmo das iniciativas de gestão que certamente estiveram presentes -, que pôs fim a essa experiência. Essa reação conseguiu restabelecer a supremacia de uma política reconduzida sobre trilhos bem conhecidos e nos papéis estabelecidos do passado: a redistribuição salarial deve ser baseada na

10 O significado desta observação pode ser melhor compreendido através do notável estudo de M. Turbiaux sobre os dramas do estabelecimento forçado do taylorismo na União Soviética nas décadas de 1920 e 1930. (Turbiaux, 2013, nota do autor).

11 Há posições diferentes a esse respeito. Ver, a título de exemplo, Carnevale (2014), que aponta Ivar Oddone como "maestro, produtor e intérprete protagonista" naquela conjuntura política, social e técnica particular (p. 40). (Nota das tradutoras)

12 Alessandra Re tece considerações sobre o declínio do movimento operário na Itália e sobre aquela conjuntura histórica, social e política, a qual ela define como irrepetível, em Pereira (2017b). (Nota das tradutoras) 
"compensação" da condição operária e nas contrapartidas sociais que expulsam a produção real e o trabalho diário para fora do "nobre" domínio da escolha política.

\section{Institucionalizar a liberdade}

O problema é que a libertação do trabalhador subordinado, sufocado, é cada vez mais atual e a cada década que passa se torna ainda mais pungente. Nenhum amortecedor social conseguirá atacá-lo pela raiz. As contrapartes não resolvem os problemas de saúde no trabalho porque o absurdo dos esforços desnecessários e o sacrifício do gosto pelo trabalho eficiente, identificados por Naville após Veblen, acabam não só por quebrar as fontes da atividade pessoal e coletiva, mas por inibir a real capacidade produtiva do trabalho moderno. A reação defensiva e conservadora do que Trentin chama de "esquerda vitoriosa" contra essa "esquerda perdedora", à qual ele certamente pertence junto com Oddone, é permanentemente ruinosa, em todos os sentidos do termo. "Valeria a pena levar em conta esta outra esquerda, até agora minoritária e derrotada, com as suas tentativas, as suas experiências e mesmo com os seus fracassos, os quais seriam indicações fortes para enfrentar os desafios atuais" (Trentin, 2012 p. 48). Porque os desafios atuais estão aí, segundo ele, para essa esquerda "trabalhista" como para todas as demais forças sociais e políticas, tanto para o sindicalismo como para os dirigentes de empresas e diretrizes gerenciais.

No entanto, devemos acrescentar uma coisa importante para completar o raciocínio de Trentin. Para ele - e creio que também para Oddone em sua época -, essa "outra alma" da esquerda é dotada de "uma melhor capacidade de sobrevivência" (Trentin, 2012, p. 43) do que a esquerda alheia ao trabalho e à empresa. É certo que esta esquerda "diferente" está dispersa e a sua presença encontra-se diluída em movimentos mal coordenados que cruzam as organizações e várias correntes de investigação e ação. Certamente ela está mal estabelecida e sua longa vitalidade é obliterada "por uma história escrita pelos vencedores" (p. 44). Mas ela está comprometida com as preocupações reais do mundo do trabalho e paradoxalmente ela "fala" mais facilmente aos trabalhadores de todos os níveis hierárquicos porque lhes fala sobre sua vida concreta; mas também de outra eficácia produtiva que desperdiçaria menos seus esforços, de outra relação com usuários e clientes, na direção do serviço prestado e do produto fabricado. Para atuar na saúde no trabalho, essa esquerda aposta no gosto pelo trabalho eficiente e na renovação de um profissionalismo "deliberado" dentro e fora da empresa em relação às novas demandas sociais por uma nova qualidade da vida e das relações com a natureza. Ela assume a qualidade do trabalho de bom grado como um traço que conecta a saúde e o desempenho. Ela pode encarar este último de frente como um motor de conflito de critérios entre funcionários e direção em relação à qualidade do trabalho, como um conflito diferente dos demais e que ainda não teve uma institucionalização à sua altura.

No mundo de hoje, que acredita poder sobreviver expandindo o trabalho subordinado e precário, privado de liberdade por uma fragmentação social explosiva, Trentin acredita que

a única riqueza relativamente estável (ou menos oscilante) que ainda pode definir a capacidade competitiva de uma empresa, de uma região ou de uma nação, refere-se, em última instância, a um trabalho inteligente e informado, capaz de resolver problemas e inovar. E dotado, justamente por isso, de novas margens de poder discricionário na esfera decisória (Trentin, 2012, p. 427).

A velha lógica compensatória da esquerda, para ele, não contará. Devemos superar as barreiras que ainda separam o trabalho da obra comum, o coletivo do individual, o trabalho da criação, "aquele da cooperação conflituosa dos trabalhadores com a gestão da empresa a partir da conquista de novas margens de autogoverno de seu trabalho" (Trentin, 2012, p. 438).

Em outras palavras, se seguirmos Trentin, precisaremos de uma "verdadeira reforma institucional da sociedade civil" (Trentin, 2012, p. 439) que mine realmente, com toda consciência, o privilégio do empregador de decidir sozinho sobre o objeto do trabalho. Pois, existe 
agora, em torno do objeto desse trabalho, sobre ele e até nele - que está cada vez mais ligado ao usuário-cliente-cidadão-consumidor -, uma

contradição explosiva entre um trabalhador, cidadão da 'polis', habilitado para o governo da 'cidade', mas privado (pelos homens, não pela natureza) do direito de buscar igualmente no trabalho a realização de si mesmo e obter sua 'independência', participando das decisões tomadas no local de trabalho e do direito a ser informado, consultado e habilitado a se expressar quanto à formulação das decisões que dizem respeito ao seu trabalho (Trentin, 2012, p. 401).

E isso sem restringi-las, mas, pelo contrário, condensando-as, tornando a capacidade do gestor de agir como o último recurso, para ampliar o raio de ação das atividades da empresa ou dos serviços. Precisaríamos, usando um vocabulário diferente, ao qual estou mais acostumado, do estabelecimento do conflito de critérios sobre a qualidade do trabalho que regenera o conflito social tradicional instalado no sistema "padrão" das relações profissionais (Clot, 2010).

Se essa direção for boa, não apenas o trabalho de Oddone e seus colegas não envelheceu, como ele pode nos ajudar a antecipar essa revolução na forma de conduzir o trabalho humano. Esse conflito de critérios certamente não é um fim em si mesmo, e sim o meio vital de uma experiência produtiva moderna, na qual o que já compartilhamos é menos interessante do que o que ainda não compartilhamos. Não é certo que a empresa possa ser o local apropriado para uma democracia de assembleia (Trentin, 2004), porque o ritmo de ação e decisão não o permitem. Mas a democracia é antes de tudo outra coisa: a instrução dos obstáculos do real por meio de controvérsias organizadas (Clot \& Gollac, 2014). Ela é também, no caso do trabalho, uma disputa profissional possível - com regras - levando ao mundo concretamente as arbitragens operacionais a serem provadas na ação; sendo validadas ou invalidadas por ela. Isso pode ser feito após a sua implementação, mas também durante e, em ambos os casos, a função de quem dirige deve ser reinventada.

De qualquer forma, o desenvolvimento criativo do poder de agir efetivo está na ordem do dia, em vez da defesa tensa de um poder forte sobre os outros, mas fraco sobre as coisas. $\mathrm{O}$ desenvolvimento dessa capacidade de agir aumenta o gosto pelo trabalho eficaz e o senso de esforço útil que conduz à saúde no trabalho. É o contrário do tempo perdido, deste tempo massivamente consumido agora nas empresas e serviços que pasteurizam conflitos do mundo real através de procedimentos ineficazes. Pensamos no Espinosa do Tratado político que, já em sua época, colocava a questão do tempo de deliberação para a ação. Acreditamos que estamos perdendo tempo na discussão, observa ele e,

sem dúvida enquanto Roma delibera, Sagunto perece, mas, por outro lado, quando um pequeno número decide tudo de acordo com suas próprias paixões, é a liberdade e o bem comum que perecem. Porque as disposições intelectuais dos homens são muito fracas para serem capazes de penetrar em tudo de uma vez. Mas elas se aprimoram no processo de deliberar, ouvir e discutir; é examinando todas as soluções que acabamos encontrando aquelas que buscamos, nas quais há unanimidade e nas quais ninguém havia pensado antes (Espinosa, 1979, IX, 14).

Soluções as quais ninguém havia sonhado antes: é para isso que pode servir o conflito de critérios instituído. Não para encontrar um compromisso ou equilíbrio entre pontos de vista já existentes, mas para vivenciar a caminhada do conhecido ao desconhecido visando ser mais eficaz. Nessa matéria, a unanimidade que pode ser alcançada, aquela que deve mesmo ser buscada, não é de forma alguma um imperativo moral. É, pelo contrário, uma ferramenta para descobrir, na ação que se segue, possibilidades práticas inesperadas. No que diz respeito à qualidade do trabalho, o único acordo duradouro é, portanto, a busca duradoura de um acordo sem trapacear com o real, que sempre mostra a falta desse acordo. É tentar direcionar a verdadeira potência do desequilíbrio, da abertura e do movimento da vida real contra a doxa estabelecida. Trata-se da saúde e do desempenho real - aquele que deciframos e não apenas aquele que quantificamos -, bem como da qualidade dos produtos fabricados e dos serviços prestados. Podemos então dizer, como A. Tosel: esse "poder instituinte só existe se for institucionalizado e se submeter a uma exigência de retificação" (2008, p. 262). 
Para manter a vitalidade institucional, tanto na empresa como no serviço ou mesmo no próprio grupo de trabalho, para evitar a degeneração tanto das atividades mais comuns como das mais pessoais, o caminho vai, portanto, dos conflitos de critérios já inventariados aos conflitos de critérios ainda não percebidos na realidade da atividade conjunta; critérios a serem decifrados juntos não sem esforço, sabendo que são a mola das institucionalizações possíveis da liberdade.

\section{Experiência indireta e psicologia}

Sem dúvida, em seu tempo, na situação social que descrevemos brevemente, I. Oddone se dedicou primeiro à constituição de um coletivo de trabalho. Não encontramos muitos elementos na descrição dessa experiência sobre as modalidades de uma cooperação conflituosa com as lideranças da Fiat. Os tempos não se prestavam a isso. Mas a preocupação com a empresa como um todo está presente no trabalho desse coletivo e é até fundamental: a confirmamos no trecho seguinte, que descreve o desenvolvimento do coletivo de trabalho dentro do chamado grupo homogêneo:

ele vai se reapropriando gradativamente, à medida que aumenta a complexidade da solução dos problemas - desde a relação do homem com a sua tarefa particular até o interesse sobre toda a empresa - de todos os modelos teóricos que informam a organização do trabalho. Esse processo de reapropriação de modelos teóricos - por meio da formação de modelos práticos extraídos da experiência e traduzidos em planos de comportamento - leva os executores a tentarem continuamente se reapropriarem de todos os modelos dos planejadores, até o modelo central, o modelo taylorista, que estão tentando modificar (1981, p. 188).

E, para fazer isso, para fomentar essa crítica prática dos critérios de gestão, os coletivos precisam desbravar seus próprios critérios de qualidade, produzi-los, inventariá-los e desenvolvêlos. Até porque esse "grupo homogêneo" que se torna protagonista da análise do meio e que garante a validação coletiva dos resultados obtidos em cooperação com especialistas não é apenas um grupo social temporário. Ele é uma história genérica: "o grupo é o portador não só da experiência bruta de seus membros, mas também daquela de quem já o deixou e, em particular, dos juízos de valor que eles estabeleceram" (1981, p. 49).

Compreendemos como Oddone avaliou bem, junto com seus interlocutores, o impasse gerado pela simples denúncia de condições de trabalho inaceitáveis, que até então era seguida na Fiat de uma demanda por salários compensatórios. A denúncia sem ação agravara a situação. A tarefa, portanto, consistia em inventar ou reinventar os instrumentos dessa ação para a saúde. Como resultado, Oddone e seus colegas buscam maneiras de ajudar os coletivos de trabalho em sua tentativa de inicialmente manter e depois expandir seu raio de ação. A psicologia do trabalho que eles praticam não busca substituir as boas ideias pelas menos boas, ou o antigo especialista pelo "bom" psicólogo ou o "bom" médico como porta-voz dos trabalhadores. Em vez disso, o especialista deve estar apto a subsidiar esse coletivo na "busca de novos critérios que permitam definir os índices de nocividade e as novas formas de participação do trabalhador" (1981, p. 35). E essa é a origem do que então foi chamado de "comunidades científicas ampliadas", capazes de construir a validação das soluções desenvolvidas. A psicologia, por sua vez, procurava identificar as condições a serem atendidas para promover a formalização e a transmissão da experiência profissional. Trinta anos depois, não mensuramos ainda todo o impacto dessa mudança de perspectiva: o centro de gravidade do trabalho de ação do psicólogo se desloca, passando do diagnóstico e do conselho à invenção de um contexto e de um dispositivo através dos quais os operadores podem começar a pensar coletivamente sobre o trabalho para reorganizá-lo. A psicologia torna-se o instrumento de mobilização subjetiva voltada para a eliminação do risco profissional: um meio vital de sustentar uma experiência coletiva de assunção do controle do trabalho por quem o faz, ou - sejamos precisos - de desenvolver os recursos comuns da atividade de cada um. 
E, nesse contexto, sempre fui muito sensível a essa observação de Oddone, aprendida nos seminários em que pela primeira vez foi utilizada a técnica das "instruções ao sósia" com trabalhadores da Fiat: ele dá ao leitor uma impressão em contradição com as verdades estabelecidas:

ficamos impressionados pelo fato de que todos os delegados - mesmo que trabalhem na linha de montagem ou na prensa - falam de seu trabalho como algo que os estimula, que desperta sua inteligência, suas habilidades psicomotoras e sua capacidade de criação (o que se deve atribuir não ao trabalho em si, mas às perspectivas que os trabalhadores sabem criar para eles mesmos). Assim, a predeterminação dos tempos e dos gestos, que é um fator de múltiplas constrições, não os faz, entretanto, chorar pelo seu destino e pelo da humanidade, mas ao contrário, os impulsiona a fazer o melhor de si e dos outros para obter mudanças. É uma luta dura e contínua, que se vive como um jogo onde nós sempre lutamos para ganhar e não para perder (1981, p. 212).

O engajamento subjetivo, assim descrito, relembra esse sujeito do odioso esforço desnecessário/descartado mencionado acima.

É um pouco do que Oddone conta quando ele recolhe, no processo de formação, as "instruções ao sósia". Porque, na verdade, nada é simples. Não há nada de espontâneo ou linear no processo de reapropriação da fábrica, de suas técnicas, de sua organização, de certos modelos e funções de concepção ou de gestão. E entendemos melhor com Oddone, a partir do interior, os obstáculos para uma ação durável, que Trentin vê, de certa forma, do exterior. Com Oddone, entramos na "caixa preta". Não há apenas a esclerose sindical e política, tampouco apenas a lógica gerencial dominante para explicar os limites do movimento de então. A atividade de reapropriação em questão não é de modo algum óbvia. Estávamos à procura, escreve Oddone, de conhecer como os trabalhadores desdobram uma experiência, estruturam os círculos concêntricos de suas atividades. E nós tínhamos dificuldade em compreender, para além das experiências vividas, "o modo de desenvolvimento" de suas experiências, continua ele. Algo nos escapou:

Era como se houvesse por trás desses comportamentos um não sei o que, feito de regras de conduta e de estratégias individuais que em parte unificava esses trabalhadores e em parte os diferenciava. Algo que eles, como sujeitos, não estavam plenamente conscientes e nós, psicólogos, não tínhamos condição de o acessar (1981, p. 55).

E esta é, sem dúvida, a principal descoberta da equipe de Oddone graças a essa experiência social. Foi preciso que eles encontrassem os meios para contornar esse obstáculo. Não é possível "recolher" diretamente a experiência: para compreender a experiência que já temos, é preciso fazer uma outra. Para compreender o já vivido, é preciso torná-lo vivo novamente. Esse é o preço do sucesso da ação. A experiência operária não pode ser reconhecida diretamente. Só a conhecemos graças a sua transformação. Para compreendê-la, devemos transformá-la. Nós apenas a vemos quando ela muda de estatuto: quando ela se torna o meio para viver outras experiências. No meu vocabulário, posso dizer que a transmissão da experiência, quando se realiza efetivamente, equivale sempre a um desenvolvimento dessa experiência. Reconhecê-la é implicá-la em uma história que a modifica. É torná-la disponível para uma história diferente daquela da qual surgiu. Agir e sobretudo ampliar seu poder de ação é usar sua experiência para fazer outras experiências. Isso é o que Bakhtin chamou exotopia. Todo o paradoxo do já vivido, para ser compreendido, talvez esteja nessas palavras "enquanto eu o estou vivendo, ele ainda não existe inteiramente" (Bakhtin, 1984, p. 126).

Oddone, de alguma forma, nos vacina contra a ilusão de que poderia ser de outra forma, que existiria um vivido em si, sem relação com a atividade "vivente" que o transforma em uma maneira de viver no presente - ou seja, contra a ilusão de que a história vivida pode existir fora de uma história que continua. Se ela não continua, ela se repete de maneira idêntica e acaba se necrosando. A retomada da experiência na instrução ao sósia é uma outra experiência, uma experiência dialógica que permitiu contornar o obstáculo. Lembramos que Bartoli, logo acima, insistiu sobre o fato que a palavra não pode somente descrever o trabalho. Ele assim o fez em 
referência à tradição cristã encarnada por Ricoeur (1953). Oddone e seus colegas levaram a sério a linguagem como atividade original. Nas sessões de instrução ao sósia, os delegados que "falam" no livro "realizam" literalmente sua experiência na fábrica endereçando-a a estes novos destinatários que são os psicólogos do trabalho. Esse contexto de análise permitiu a esses trabalhadores redescobrir a experiência operária para tê-la à disposição da consciência. A obra de Oddone pode assim ser vista como a fonte, sem a qual o movimento de criação coletiva analisado por Trentin não pode perdurar.

\section{A instrução ao sósia ou as virtudes da inquietude}

Este parece ser mesmo o espírito do trabalho de Oddone: não há reapropriação da fábrica sem reapropriação da própria experiência. E podemos nos perguntar por que esse psicólogo ${ }^{13}$ não toma emprestada nenhuma referência de Vigotski, mesmo que este último esteja presente na ideia de que "a representação de um sósia é a representação da consciência mais próxima da realidade" (Vigotski, 2003, p. 91). Vigotski, a quem devemos a formulação segundo a qual a linguagem não expressa o pensamento, mas o realiza, fornece os meios para melhor compreender o que acontece nas instruções ao sósia quando, ao se colocar no lugar do outro, os delegados percebem que há um devir da experiência nas palavras; essas palavras que eles colocam ao trabalho respondendo, como instrutores, a esta questão do sósia: Eu tenho que substituí-lo amanhã, diga-me como terei que fazer para que ninguém perceba que não sou você $\hat{e}^{14}$. Vigotski, no final de Pensamento e linguagem, comenta os versículos da Bíblia: No início era o Verbo, segundo a palavra do Evangelho. E a réplica de Goethe, buscando menosprezar a palavra na voz de Fausto, é cortante: No início era a ação. Mas, escreve Vigotski, existe uma outra via. Podemos enfatizar o versículo bíblico de forma diferente se o considerarmos do ponto de vista do desenvolvimento. No início era a ação: "A palavra não estava no princípio. No princípio era a ação. A palavra constitui o fim e não o começo do desenvolvimento. A palavra é o fim que coroa a obra" (Vigotski, 1997, p. 499) ${ }^{15}$.

Revisitada a partir da psicologia vigotskiana, a estrutura clínica da ação proposta na instrução ao sósia teve uso significativo na França. Em certo sentido, esta é uma contribuição técnica alternativa para as estratégias de "escuta psicológica" discutidas acima. A entrevista terapêutica pode ser muito degradada em situação de trabalho. Ela merece coisa melhor. A instrução ao sósia, por outro lado, "apoia" descrições que teriam surpreendido o próprio Oddone se pudessem ser submetidas a ele. Isso porque, embora tão técnica, ela realmente redescobre fortes intuições filosóficas. Citaremos duas. A primeira vem de S. Kierkegaard, que entende A retomada como um desenvolvimento (2008, pp. 238-239): a vida deve ser bem compreendida olhando para trás. Mas não se pode esquecer que deve ser vivida olhando para frente (Kierkegaard, 2008, p. 183). Razão pela qual no presente a vida nunca é completamente compreensível, porque em nenhum momento podemos alcançar a tranquilidade que nos permite tomar tal posição. Essa inquietação é, sem dúvida, uma das principais construções da instrução ao sósia quando praticada. Encontramos isso na observação de W. Gombrowicz: "Talvez eu tivesse conseguido alcançar meu passado, se o presente apenas tivesse parado de continuar" (1995, p. 336). Isso nunca é o caso. O arcabouço técnico da instrução ao sósia assume esse

13 Embora a formação de Oddone fosse em Medicina, ele compreendeu que essa não poderia lhe fornecer as ferramentas necessárias para lidar com as questões aqui discutidas, tendo buscado na Psicologia as referências para tanto e passado a se identificar como psicólogo do trabalho, conforme discutido em Pereira (2017a). (Nota das tradutoras)

14 Essa pergunta certamente pode variar um pouco, mas sempre mobiliza o passado para o futuro. Para ir mais longe no conhecimento técnico no contexto assim proposto, além de ler a obra Esperienza operaia, coscienza di classe e psicologia del lavoro, que continua a ser a referência, também se pode consultar O trabalho sem homem? (Clot, 1995), A função psicológica do trabalho (Clot, 1999) ou Trabalho e poder de agir (Clot, 2008) (Nota do autor).

15 A dificuldade de "coroar a obra" até o final na experiência Fiat não está sem razão no simples esquecimento lamentado por Trentin. Em certo sentido, a obra de Oddone é a prova concreta da proposta de Vigotski: ela coroa - como a de Trentin à sua maneira - a obra comum dos trabalhadores da Fiat e da equipe de Oddone, por fazer de sua memória um meio de agir em um novo contexto que é o nosso (Nota do autor). 
conflito vital, busca esse advento da intranquilidade na experiência da análise do trabalho tanto no nível individual quanto coletivo (Reille-Baudrin \& Werthe, 2010; Werthe \& Ouvrier Bonnaz, 2012). Esse advento é uma fonte de criação potencial porque coloca o sujeito uma cabeça acima de si mesmo, para falar como Vigotski. E isso tem várias consequências psicológicas.

Nas apresentações habituais dessa técnica na França, e durante muito tempo, nos esforçamos para mostrar, assim como eu acabo de fazer acima, a função da linguagem nessa tomada de consciência de que a experiência habitual é inacabada (por exemplo, Bournel-Bosson, 2006; Clot, 1995, p. 179; Clot, 1999, p. 152; Clot, 2008, p. 178; Scheller, 2003). Mas acho que também podemos deslocar a ênfase na compreensão dos mecanismos em funcionamento na instrução ao sósia. A moldura clínica desta "transmissão" procura provocar a experiência afetiva que Canguilhem identificou nesta observação: "por vida, pode-se entender o particípio presente ou particípio passado do verbo viver, o vivente e o vivido. A segunda acepção é, na minha opinião, comandada pela primeira, a qual é mais fundamental" (Canguilhem, 1983, p. 335). A primazia é bem marcada aqui. Oddone a instalou sem realmente se ater a ela: é a atividade vivente em curso no contexto da transmissão das instruções ao sósia que mobiliza ou imobiliza a atividade já vivida pelo instrutor. Essa exigência de trabalho é primeiro uma prova afetiva na medida em que engaja os sujeitos envolvidos nesta caminhada do conhecido para o desconhecido já mencionada acima; em uma "passagem" da atividade profissional, que é uma colisão entre seus esperados e inesperados "produzida" pelo sósia. A prática da experiência mostra isso: esta prova desestabiliza a organização do sujeito ao colocar a atividade em conflito consigo mesma. Na verdade, o instrutor é convocado a dizer ao outro o que ele deve fazer em uma situação futura, apenas por meio do que ele faz habitualmente. $\mathrm{O}$ inesperado encarnado pela imaginação necessária do sósia desconcerta o instrutor. $\mathrm{O}$ afeto emerge quando este último persiste, sem sucesso, em olhar para trás para instruir um sósia que tenta viver olhando para frente, para falar como Kierkegaard.

Nessa troca vivente "puxada" pelo desconhecido que se tenta domar, o que excede ultrapassa os esquemas conhecidos pelo instrutor, inibe-os ou, inversamente, é confiscado por eles, é assinalado pelo afeto. Este se apresenta então como o impacto da atividade vivente em curso com o sósia no já vivido do instrutor. Quando um objeto ou um destinatário inesperado, por iniciativa do sósia, invade o previsto do instrutor, sua organização psicológica perde sua contenção habitual. Ele é, então, levado aos limites, eventualmente além do repertório do gênero profissional que ele dispõe. O conflito leva-o a se descobrir ao opor nele passividade e atividade na proporção de seus afetos, que descarregam ou recarregam suas energias. Esse contragolpe muda a temperatura da atividade em curso na instrução. Ele pode se produzir para o benefício eventual da descoberta de algo novo, mas também sob risco de defesas ansiosas dos hábitos do trabalho. É, naturalmente, através da linguagem que operam esses processos afetivos, mas não somente (Poussin, 2014). É através do diálogo que o instrutor percebe como o que ele diz ao sósia sobre seu trabalho habitual convida-o, em troca, a fazer algo diferente do que ele mesmo se ouve dizer, tanto em seu diálogo interior (Scheller, 2003) e até depois. Assim, como observado por Vigotski, ele pode experimentar também, pelo menos algumas vezes, que o hábito, tal como está instalado, como é regularmente realizado, "é apenas uma pequena parte do que é possível" e que, como instrutor, ele "está pleno, a cada minuto, de possibilidades não realizadas" (Vigotski, 2003, p. 76). Vemos, então, a que ponto a motricidade do afeto na atividade conjunta (Clot, 2015a; 2015b) é o coração da instrução ao sósia (Poussin, 2014; Reille-Baudrin, 2011; Scheller, 2003).

\section{O trabalho continua}

Diríamos que estamos muito distantes da experiência da Fiat. Eu não acredito. Pois é possível supor seriamente que é assim que a experiência de trabalho dos delegados que "falam" na obra de Oddone é reinventada, e não apenas contada. Ao contrário da narrativa, que sempre corre o risco de se tornar um "amortecedor do inesperado" (Bruner, 2014, p. 44), essa técnica é indissociável de uma metodologia de desenvolvimento em psicologia que cultiva a multifuncionalidade concreta da linguagem para desenvolver o pensamento (Kostulski, 2011, 
2012). Atualmente, ela é amplamente utilizada na França em uma ampla variedade de contextos de intervenção e análise. Encontramos, por exemplo, e entre outros, os resultados apresentados em diferentes profissões: de professores com seus alunos (Ruelland-Roger \& Clot, 2013; Saujat et al., 2008), a engenheiros industriais (Miossec, 2011), de técnicos a gerentes de serviço (Miossec et al. 2010; 2015), de cuidadores (Agero, 2015; Bourret, 2011) a inspetores de trabalho e controladores (Reille-Baudrin \& Werthe, 2010), de médicos do trabalho (Fernandez, 2009) a empregados (Scheller, 2003). Cada vez essa técnica dá uma história às palavras dentro das palavras (Bournel-Bosson, 2006; Faïta, 2011;Henry \& Bournel-Bosson, 2008). Mas também encontramos a instrução sósia na formação de psicólogos do trabalho no CNAM, várias dezenas deles a cada ano, segundo um protocolo que vai do oral ao escrito, desempenhando precisamente as múltiplas funções da linguagem (Kostulski, 2011; Reille-Baudrin, 2011; Scheller, 2003).

Contudo, um último ponto merece ser sublinhado. O uso da instrução ao sósia está longe de ser o único legado técnico de I. Oddone. A reapropriação do meio profissional com vistas à preservação da saúde não passava para ele apenas por essa prova psicológica singular, ao contrário. E o trabalho que ele desenvolveu até sua recente desaparição viu outras inovações pelo mesmo caminho de mobilizar na experiência dos trabalhadores o imenso potencial de informações que ela guarda. Devemos a ele em particular, em colaboração com A. Re, professora de ergonomia na Universidade de Torino, o desenvolvimento de um sistema de informação concreto no complexo industrial de Fos e na lagoa de Berre. Esse sistema, novamente baseado na dupla trabalhador-médico, desta vez em nível municipal, estrutura uma experiência iniciada e mantida há cerca de vinte anos na França por M. Andéol, R. Crucciani e G. Igonet (Andéol et al., 2015). Essa experiência, que ainda faz o trabalho "falar", mantém o mesmo sentido do projeto concreto de Oddone, uma aliança de inovação e resistência. Ela mobiliza outras técnicas para formalizar a experiência dos trabalhadores em saúde do trabalhador, como "colocar online o cadastro municipal do risco comprovado". Encontramos ressonâncias muito informadas disso no estudo que R. Vasconcelos e M. Lacomblez (2005) dedicaram à obra de Oddone. Essa experiência, mais uma vez, possibilita desenvolver a iniciativa dos trabalhadores, pois é condição para sua saúde.

No fundo, essa experiência mais recente, como a da Fiat nas décadas de 1960 e 1970, ou mesmo a que se desenvolve no CNAM há mais de vinte anos, mostra a cada vez que o trabalho não é apenas um problema, mas também uma solução: a experiência dos trabalhadores pode servir a outros fins que não os seus. Pode, por exemplo, participar da renovação institucional do sistema de saúde, como em Fos, pode delinear a possibilidade de um novo sistema de relações profissionais (Bonnefond et al., 2015). A responsabilidade pelo ato, o prazer de sentir-se responsável por algo para além de si mesmo é, sem dúvida, a chave do compromisso de I. Oddone. É por isso que esse compromisso científico e social permanece muito moderno em um momento em que se busca uma cooperação conflituosa entre assalariados e direção para gerir a empresa de forma diferenciada e fazer da qualidade do trabalho o meio de uma nova qualidade de vida. Nesse novo contexto, os obstáculos que se colocam no caminho aberto por Oddone permanecem quase intransponíveis. Mas são também esses obstáculos que podem, paradoxalmente, enriquecer ainda mais a experiência de quem trabalha. Mulheres e homens percebem as desvantagens do absurdo e do desperdício de sua experiência profissional, escreveu Naville em 1955. Essa ideia está ganhando espaço: nas organizações, o trabalho merece ser requalificado, sua qualidade discutida em instituições à sua altura, e as "relações humanas" têm muito a ganhar ao "se refazerem" a partir desse trabalho cuidado. Quarenta anos depois de Mayo, existe Oddone. Trinta e cinco anos após Oddone, o trabalho continua.

\section{Referências}

Agero, M. (2015). Développement du pouvoir d'agir et genre professionnel: le métier des agents communautaires au Brésil.

Thèse pour le doctorat de psychologie du travail. Conservatoire National des Arts et Métiers. 
Andéol, M., Cruciani, R., \& Re, A. (2015). Le système d'information concret (SIC). In A. Thébaud-Mony, P. Davezies,

L. Vogel, \& S. Volkoff (Eds.), Les risques du travail (pp. 447-450). La Découverte.

Bakhtin, M. (1984). Esthétique de la création verbale. Gallimard.

Bartoli, H. (1957). Chronique de la pensee economique en Italie. Rerue économique, 8(1), 146-152. doi:10.2307/3498142

Bellashen, M. (2014). La santé mentale. Vers un bonheur sous contrôle. La fabrique.

Bonnefond, J. Y., Clot, Y., \& Scheller, L. (2015). Pour une psychologie de l'initiative professionnelle, une expérience à Renault-Flins. Psychologues Eु Psychologies, 239, 25-30.

Bournel B., M. (2006). Analyse de l'activité et mouvements dialogiques dans le cadre de l'instruction au sosie. Pratiques Psychologiques, 12, 31-43.

Bourret, P. (2011). Prendre soin du travail. Un défi pour les cadres à l'hôpital. Pour sortir le travail réel de son invisibilité. Seli Arslam.

Bruner, J. (2014). Culture et esprit: une féconde incommensurabilité. In C. Moro \& N. Muller Mirza (Eds.), Sémiotique, culture et développement psychologique (pp. 165-185). Septentrion.

Centre d'analyse stratégique. (2010). La santé mentale, affaire de tous. Pour une approche cohérente de la qualité de vie. La Documentation française.

Canguilhem, G. (1983). Etudes d'histoire et de philosophie des sciences. Vrin.

Canguilhem, G. (2015). Résistance, philosophie biologique et histoire des sciences. Euvres complètes, tome IV. Vrin.

Castel, R. (2011). La Gestion des risques. De l'antipsychiatrie à l'après-psychanalyse. Éditions de Minuit.

Clot, Y. (1995). Le travail sans l'homme? Edition de poche 2008. La découverte.

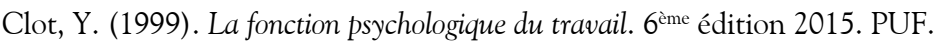

Clot, Y. (2008). Travail et pouvoir d'agir. PUF.

Clot, Y. (2010). Le travail à cour. Pour en finir avec les risques psychosociaux. Edition de poche 2015. La découverte.

Clot, Y. (2015a). Vygotski avec Spinoza au-delà de Freud? Revue philosophique, 2, 205-223.

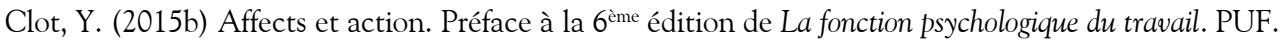

Clot, Y. (2017). L'affectivité en activité. In J. M. Barbier \& M. Durand (Eds.), Encyclopédie de l'analyse des activités (pp 131-151). PUF.

Clot, Y. \& Gollac, M. (2014). Le travail peut-il devenir supportable? A. Colin.

Cottraux, J. (2012), Psychologie positive et bien être au travail. Elsevier-Masson.

Faïta, D. (2011). Théorie de l'activité langagière. In B. Maggi (Ed.), Interpréter l'agir. Un défi théorique (pp. 41-67). PUF.

Fernandez, G. (2009). Soigner le travail. Erès.

Friedmann, G. (1946). Problèmes humains du machinisme industriel. Gallimard.

Getz, I. (2012). En quête d'entreprises jouant la liberté et le partage du rêve. Journal de l'Ecole de paris du management, 3, $95,8-15$.

Gombrowicz, W. (1995). Le Journal, II. Gallimard.

Henry, M. \& Bournel-Bosson, M. (2008). La vie des mots en analyse du travail. Activités, 5(2), 25-39.

Illouz, E. (2006). Les sentiments du capitalisme. Seuil.

Kierkegaard, S. (2008). La Reprise. Flammarion.

Kitanaka, J. (2014). De la mort volontaire au suicide au travail. Ithaque.

Kostulski, K. (2011). Pour une psychologie concrète du langage. Document pour l'HDR en psychologie. Université Paris VIII.

Kostulski, K. (2012). La diversité fonctionnelle du langage: usages et conflictualités dans l'activité. In Yves Clot (Dir.), Vygotski maintenant (pp. 361-378). La Dispute.

Leplat, J. (1982). Compte rendu de Redécouvrir l'expérience ouvrière. Le Travail Humain, 45(2), 373. 
Linhart, D. (2015). La comédie humaine du travail. De la déshumanisation taylorienne à la sur-humanisation managériale. Erès.

Mayo, E. (1945). The Social Problems of an Industrial Civilization. Harvard University.

Miossec, Y. (2011). Les instruments psychosociaux de la santé au travail. Le cas des managers de proximité de l'industrie électrique. Thèse pour le doctorat en psychologie. Conservatoire National des Arts et Métiers.

Miossec, Y., Clot, Y., \& Boucher, C. (2015). L'intervention dialogique pour agir sur les risques psychosociaux: une troisième voie. In L. Lerouge (Ed.), Approche interdisciplinaire des risques psychosociaux au travail (pp. 51-66). Octares.

Miossec, Y., Donnay, C., Pelletier, M., Zittoun, M. (2010). Le développement du métier: une autre voie de prévention des risques psycho-sociaux. L'exemple d'une coopération entre médecins et psychologues du travail, Nouvelle revue de psychosociologie, 10, 195-209.

Naville, P. (1955/2012). Essai sur la Qualification. Syllepse.

Oddone, I., Re, A., \& Briante, G. (1981). Esperienza operaia, coscienza di classe e psicologia del lavoro. Einaudi.

Oddone, I., Re, A., \& Briante, G. (1981). Redécouvrir l'expérience ouvrière : vers une autre psychologie du travail? Les éditions sociales.

Poussin, N. (2014). Développement des sentiments au travail: dialogues sur l'efficacité et l'utilité chez des médecins du travail. Thèse pour le doctorat de psychologie. CNAM.

Reille-Baudrin, E. (2011). Reconversion professionnelle, l'espace d'une transition: d'une clinique de l'expérience à l'expérimentation clinique de l'activité transitionnelle: la méthode des instructions au sosie. Thèse pour le doctorat en psychologie. CNAM.

Reille-Baudrin, E. \& Werthe, C. (2010). Le développement du collectif: un moyen durable de prévention en santé au travail. Nouvelle revue de psychosociologie, 10, 209-223.

Ricoeur, P. (1953). Travail et parole, Esprit, 1, 96-117.

Ruelland-Roger, D. \& Clot, Y. (2013). L'activité réelle de l'élève: pour développer l'activité enseignante. Revue internationale du Crires. Innover dans la tradition de Vygotski, 1 (1), 12-19.

Saujat, F., Barrère, A., \& Lantheaume, F. (2008). Rendre visible le travail enseignant. Questions de méthodes. Recherche et formation, 57.

Scheller, L. (2003). Elaborer l'expérience du travail : activité dialogique et référentielle dans la méthode des instructions au sosie. Thèse pour le doctorat de psychologie. CNAM.

Spinoza, B. (1979). Traité politique. Réplique. (Trabaho original publicado em 1677)

Supiot, A. (2012). Introduction. In B. Trentin (Ed.), La Cité du travail. Le fordisme et la gauche. Fayard.

Tosel, A. (2008). Spinoza ou l'autre (in)finitude. l'Harmattan.

Trentin, B. (2004). La libertà viene prima. Editori Riuniti.

Trentin, B. (2012). La Cité du travail. Le fordisme et la gauche. Fayard.

Turbiaux, M. (2013). Sous le drapeau rouge: la conférence internationale de psychotechnique de Moscou de 1931. $1^{\text {er }}$ $\& 2^{\text {ème }}$ partie. Bulletin de psychologie, 66, 527 -528.

Vasconcelos, R. \& Lacomblez, M. (2005). Redescubramo-nos na sua experiência: O desafio que nos lança Ivar Oddone. Laboréal, 1(1), 38-59.

Werthe, C. \& Ouvrier-Bonnaz,. (2012) L'instruction au sosie en formation, le collectif dans l'individuel. Carriérologie, 12(3-4), 509-521.

Vigotski, L. (1997). Pensée et langage. La Dispute.

Vigotski, L. (2003). Conscience, inconscient, émotions. La Dispute. 


\section{Referências acrescidas na tradução}

Carnevale, F. (2014). Salute dei lavoratori, tecnologie, conflitti. In A. Re, T. Callari, \& C. Occelli (Eds.), Sfide attuali, passate, future: il percorso di Ivar Oddone (pp. 33-40). Otto.

Oddone, I. \& Re, A. (2017). Como recuperar o saber profissional. Trabalho Ė Educação, 26(3), 29-33.

Pereira, M. S. (2017a). Movimento Operário Italiano, Ivar Oddone e a Instrução ao Sósia. Trabalho Ė Educação, 26(3), 13-27.

Pereira, M. S. (2017b). Entrevista: Alessandra Re. Cadernos de Psicologia Social do Trabalho, 20(2), 203-212. https://doi.org/10.11606/issn.1981-0490.v20i2p203-212

Endereço para correspondência

matildeagero@yahoo.com.br
Recebido em: 23/12/2020

Revisado em: 06/05/2021

Aprovado em: 15/07/2021 